\title{
Medical decision, persistence of initial treatment, and glaucoma progression in a Brazilian reference hospital
}

\author{
Decisão médica, persistência com o tratamento inicial e progressão do \\ glaucoma em um hospital de referência no Brasil
}

\author{
Jayter Silva Paula ${ }^{1}$ \\ José Afonso Ramos Filho ${ }^{2}$ \\ Daniel Felipe Alves Cecchetti ${ }^{3}$ \\ Daniela Tiemi Nagatsuyu ${ }^{4}$ \\ Maria de Lourdes Veronese Rodrigues ${ }^{5}$ \\ Eduardo Melani Rocha ${ }^{6}$
}

\begin{tabular}{l} 
ABSTRACT \\
\hline Purpose: To evaluate the initial medical decision regarding primary \\
open-angle glaucoma (POAG) treatment in a referral center, and to assess the \\
relationship between the persistence of treatment and the disease pro- \\
gression in cases managed exclusively with medication. Methods: A \\
retrospective chart review was performed for 65 patients with primary \\
open-angle glaucoma referred to a tertiary hospital. The following clinical \\
data were analyzed: initial medication, persistence of treatment, best \\
corrected visual acuity, visual field mean deviation index, cup/disc ratio, \\
and intraocular pressure. Patients were classified into four categories in \\
order to verify the clinical evolution. Results: The mean number of visits/ \\
yearwas $4.4 \pm 3.5$, and the follow-up period was $40.7 \pm 22.8$ months. Mean \\
persistence time was $12.9 \pm 13.9$ months. By six and twelve months, res- \\
pectively, $39.1 \%$ and $62.5 \%$ of patients had discontinued the initially \\
prescribed regimen, mainly by adding to (42\%) or changing (26\%) the \\
course of treatment. Thirteen patients (21\%) were reclassified to a worse \\
category of primary open-angle glaucoma, however, despite this trend, no \\
significant correlation was found between shorter persistence and primary \\
open-angle glaucoma worsening. Conclusions: Persistence rates with \\
initial therapy schemes were low, as measured by medical decisions to \\
change the course of treatment. Therefore, improvement in the initial \\
medical decision is crucial in order to offer a more stable and effective \\
treatment for primary open-angle glaucoma. \\
\hline
\end{tabular}

Keywords: Glaucoma, open-angle/drug therapy; Intraocular pressure; Blindness/prevention \& control; Attitude to health; Communication; Patient compliance; Physician-patient relations; Disease progression

\section{INTRODUCTION}

Glaucoma is a chronic disease and a major cause of blindness. Currently, the only evidence-based mode of treatment is to control intraocular pressure (IOP) ${ }^{(1-3)}$. Treatment persistence is defined as total length of time on a defined therapy and is a key element in disease progression, which involves not just patient adherence to medical recommendations but also medical decisions ${ }^{(4-5)}$.

Medical decisions may be guided by the clinical control of the disease, economic realities for the patient and health care provider, the intensity of adverse effects, and market influences ${ }^{(6)}$. The consequence for Primary Open-Angle Glaucoma (POAG) is that longer persistence is also associated with the number of days of controlled IOP since every change is preceded by a instability period and followed by an uncertain period of adaptation. 
Moreover, longer persistence reduces costs for the patient and for the health care system ${ }^{(1,7-8)}$. The multitude of options for glaucoma treatment and difficulty in predicting the patient's response to treatment make it difficult to adopt a strategy with an adequate persistence ${ }^{(9-10)}$.

University hospitals work as referral centers for more complex cases of POAG, and therefore a shorter persistence would be predicted in this environment ${ }^{(11-13)}$. However, it is more important in these situations to know the persistence time of initially prescribed antiglaucomatous medications and to make efforts to improve medical decisions, including planning for the long-term course of chronic disease treatment. Improved initial treatment schemes would be helpful from both health and economic perspectives ${ }^{(14)}$.

The objective of the present study was to investigate the persistence time of the first adopted therapy (i.e., initial medical choice) at a referral university hospital. The ocular profile of patients admitted and the progression of POAG at a glaucoma clinic in a tertiary level hospital in Brazil were also evaluated.

\section{METHODS}

This retrospective chart review study was conducted to evaluate the clinical profile at admission and the initial medical antiglaucoma therapy prescribed or maintained for POAG patients referred to a tertiary level hospital in southeastern Brazil. The persistence time of initial therapy and the parameters of disease progression were also analyzed.

Medical records were reviewed for patients who had been referred to a tertiary hospital between 2000 and 2004 with primary open-angle glaucoma diagnosis. Patients without previous ocular surgery and with maintenance or initiation of glaucoma therapy were included. Patients were excluded if they had any ocular procedure other than antiglaucomatous surgery during the follow-up period, if they failed to attend follow-up visits, or if they were suspected of having secondary glaucoma. This study was conducted according to the Declaration of Helsinki and was approved by the Institutional Ethics Committee.

The following data were recorded: age, gender, best corrected visual acuity (BCVA) (decimal scale), intraocular pressure (IOP), vertical optic cup/disc ratio (CD), automated visual field (MD - mean deviation index, Humphrey Visual Field Analyzer II - 750, 24-2 program, SITA, Humphrey Systems, Dublin, CA, USA), prescribed drugs, persistence time of initial therapy, number of visits per year, changes in the number of medications, and total follow-up period. BCVA, IOP, CD, and MD were recorded at the first and last visits. The study included patients who made their first visit between January of 2000 and December of 2004 and had a follow-up period longer than 12 months. Data from the last visit were defined as the last exam recorded in the patient file at that institution.

For the purpose of this study, POAG was defined as a high IOP, a normal anterior chamber with an open angle, glaucomatous optic disc damage or suspicion of such damage, and a visual field defect. The persistence time of the initial treatment was defined as the period between the first visit at the tertiary hospital and the visit when treatment was discontinued as per medical decision, whether by addition, exclusion, or substitution of antiglaucomatous medications, or if an indication for laser or surgical glaucoma treatment was made. Changes in the frequency, commercial name or dosage of the same medication used were not considered as persistence failures. One eye per patient was selected for this study, and when patients presented with bilateral glaucoma, data for the best eye (based on the best visual acuity) were recorded.

Based on visual field damage (MD) and CD, glaucoma was classified into one of the following four stages: stage 0: $C D<0.4$ or MD <-2.5; stage I: CD between 0.4 and 0.7 or MD between -2.5 and -5.0 ; stage II: CD between 0.8 and 0.9 or MD between -5.1 and -8.0 ; and stage III: $\mathrm{CD}>0.9$ or MD > -8.0 (modified from Eid et al., 2003 $)^{(15)}$. Whenever a discrepancy was found between the optic disc cup and MD, the optic disc cup was considered for staging and analysis. The number of patients who experienced a worsening of glaucoma from one stage to the next was evaluated, except for patients who were first classified as the worst stage. The worsening rate was plotted against the persistence of the initial treatment for a period of 6 months or less.

Data were analyzed statistically and presented as mean \pm standard deviation. The persistence of initial treatment at the referral center was analyzed by a Kaplan-Meier survival curve. The association between low persistence ( $<6$ months) and worsening of glaucoma was evaluated by Fisher's exact test. Possible independent predictors of persistence were analyzed using a multivariate model (SPSS 16.0, SPSS Inc.) for all co-variables.

\section{RESULTS}

Of the 65 studied patients, 32 were female and 33 were male. Mean age was $66.0 \pm 12.7$ years, mean initial BCVA was $0.6 \pm 0.3$, initial MD was $-11.8 \pm 9.2$, initial $C D$ was $0.6 \pm 0.2$, and initial IOP was $21.6 \pm 6.8 \mathrm{mmHg}$. Patients had a mean of $4.4 \pm 3.5$ visits per year and a follow-up period of $40.7 \pm 22.8$ months. During the follow-up period, the variation was $-0.05 \pm$ 0.19 in BCVA, $-0.04 \pm 6.6$ in MD, $-5.5 \pm 7.0 \mathrm{mmHg}$ in IOP, and $0.1 \pm 0.1$ in $\mathrm{CD}$ (Table 1).

Twenty-eight (43\%) patients arrived without any treatment, whereas $37(57 \%)$ were receiving a previous treatment. At the initial visit, only three patients were kept with no medications, including one patient who underwent trabeculectomy. Of the other 62 treated patients, $37(59.7 \%)$ were treated with multidrug therapy. Initially prescribed monotherapies included betablockers $(32.3 \%)$, prostaglandin analogues $(3.2 \%)$, alpha agonists (3.2\%), and pilocarpine (1.6\%) (Table 2).

During the initial visit at the referral center, $9(13.8 \%)$ patients were in stage $0,44(67.7 \%)$ in stage I, $9(13.8 \%)$ in stage II, and $3(4.6 \%)$ in stage III. 


\begin{tabular}{|c|c|c|}
\hline Parameter & At presentation & Variation \\
\hline Best corrected visual acuity & $0.6 \pm 0.3$ & $-0.05 \pm 0.19$ \\
\hline Cup/disc ratio & $0.6 \pm 0.2$ & $0.10 \pm 0.10$ \\
\hline Mean deviation index & $-11.8 \pm-9.2$ & $-0.04 \pm 6.60$ \\
\hline Intraocular pressure $(\mathrm{mmHg})$ & $21.6 \pm 6.8$ & $-5.50 \pm 7.00$ \\
\hline
\end{tabular}

\begin{tabular}{l}
$\begin{array}{l}\text { Table 2. Initial treatment scheme prescribed at first visit in a } \\
\text { Brazilian tertiary hospital between } 2000 \text { and } \mathbf{2 0 0 4}\end{array}$ \\
$\begin{array}{lr}\text { Number of patients (\%) } \\
\text { BB - Timolol } & 18(29.0 \%) \\
\text { BB - Betaxolol } & 2(3.2 \%) \\
\text { PA - Bimatoprost } & 2(3.2 \%) \\
\text { Pilocarpine } & 1(1.6 \%) \\
\text { Brimonidine } & 2(3.2 \%) \\
\text { BB + Brimonidine } & 10(16.1 \%) \\
\text { BB + Pilocarpine } & 9(14.5 \%) \\
\text { BB + CAl } & 4(6.5 \%) \\
\text { BB + PA } & 6(9.7 \%) \\
\text { Pilocarpine + CAl } & 2(3,2 \%) \\
\text { Three drugs or more } & 6(9.7 \%) \\
\text { BB= beta-blockers; PA= prostaglandin analogues; CAl= topical carbonic } \\
\text { anhydrase inhibitor }\end{array}$ \\
\hline
\end{tabular}

Figure 1 illustrates the persistence of the initial treatment. The mean persistence time was $12.9 \pm 13.9$ months. At six and twelve months, respectively, $39.1 \%$ and $62.5 \%$ of patients had discontinued the initially prescribed therapeutic scheme. Changes to the initial treatment scheme were: inclusion of a new medication for 27 patients (42\%), filtering surgery in 11 patients (17\%), reduction of the number of medications in 2 patients (3\%), complete change of all initial drugs in 17 patients (26\%), and maintenance on the initial scheme in 8 patients $(12 \%)$. The variation of number of drugs between initial prescription and the first change was $0.15 \pm 1.0$ medications.

Thirteen patients (21\%) were reclassified to a worse glaucoma category. An association was observed between patients who experienced clinical worsening and shorter persistence of the initial therapy (i.e., within the first six months), however, this relationship was not statistically significant (Fisher's exact test, $\mathrm{P}=0.113$ ). Although univariate analysis of the co-variables initial MD, initial $\mathrm{CD}$, and number of visits per year displayed significantly higher values in the shorter persistence group $(\mathrm{P}<0.01, \mathrm{P}=0.049$ and $\mathrm{P}<0.01$, respectively), multivariate statistics did not show a significant correlation with persistence.

\section{DISCUSSION}

This report presents a description of the initial medical therapy prescribed for patients with POAG in a referral center in Brazil. To better understand what underlined the initial

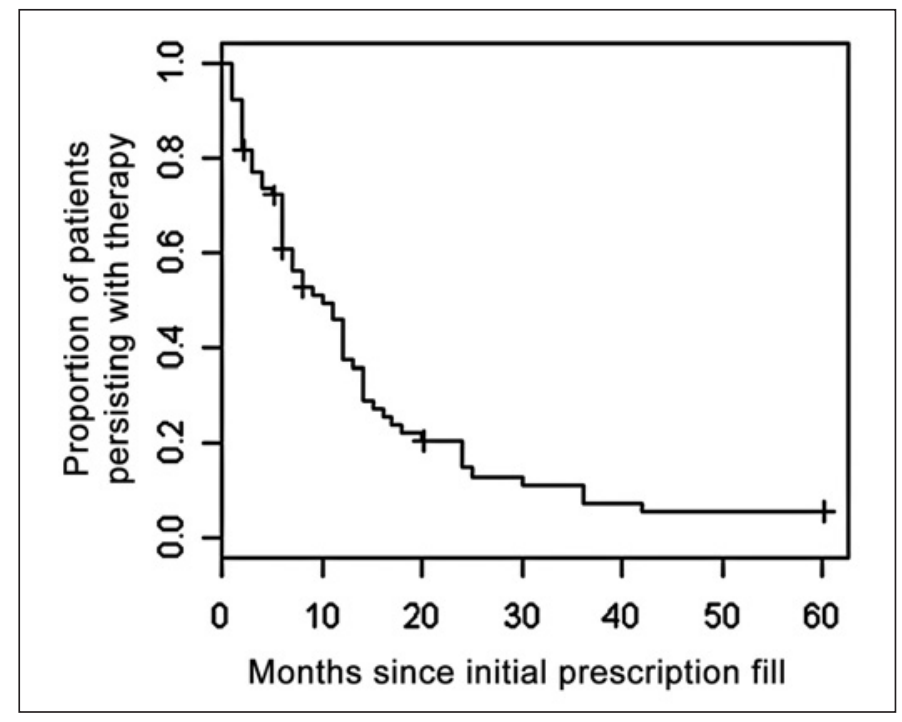

Figure1 - Kaplan-Meier plot for time to discontinuation of ocular hypotensive therapies in a Brazilian tertiary hospital between 2000 and 2004

decision, the clinical profiles of patients were investigated. The lengths of time before changing the initial recommended therapy and any changes in the initial clinical glaucoma parameters during the treatment period were also reported.

Most of the tertiary ophthalmology referral centers in Brazil are part of the public health system, with universal access, and free of cost to the patient. These centers are responsible for the treatment of the majority of POAG cases in the country. Compared to previous studies conducted at other tertiary hospitals in southeastern Brazil, our data showed a patient pool with a similar age distribution, gender ratio, and IOP levels; better visual acuity; and moderate glaucoma defects in the visual field ${ }^{(11,13,16)}$.

In 2001, the Brazilian Society of Glaucoma published a Guideline for Diagnosis and Treatment of POAG. The second version of this publication promoted beta-blockers as the first line of monotherapy, and considered prostaglandins as a second option, depending on the economic status of the patient ${ }^{(17)}$. Therefore, similarly to other referral centers, monotherapy with beta-blockers was the most prevalent antiglaucomatous treatment ${ }^{(16,18-19)}$.

This recommendation and treatment trend could be justified since beta-blockers became the leading pharmacologic treatment for glaucoma soon after they were introduced in 1978 as a result of their effectiveness, local tolerability, low cost, and relative dosing convenience. However, ocular surface side effects have been associated with this treatment as well as with other topical antiglaucoma treatments ${ }^{(20)}$.

Most treatment outcomes reported for glaucoma reflect only a short-term follow-up. In the Advanced Glaucoma Intervention Study (AGIS), some authors (2004) showed a 30\% mean worsening of the visual field after two years ${ }^{(21)}$. A few long-term studies have shown rates of worsening up to $81.4 \%$ after 20-years follow-up ${ }^{(15)}$. Over a mean follow-up period of 
40 months, we observed that approximately $21 \%$ of patients worsened to another glaucoma category. The absence of a universal criterion for assessing glaucoma progression, together with recent changes in exam protocol, make difficult the evaluation on a population-wide basis.

There were several factors that this retrospective study was unable to determine, including the reasons that led ophthalmologists in this referral hospital to decide on a therapy other than beta-blockers, as well as the reasons for early changes in POAG medication. These factors could include socio-economic issues, clinical severity at the first visit, risk of side effects and also marketing by pharmaceutical industries ${ }^{(6-7,22)}$. Moreover, our study was unable to evaluate differences in persistence based on initial medication since almost all patients were initially treated with beta-blockers. In the same way, the multitude of treatment options and circumstances made it impossible for us to identify a preferred drug after the initial therapy change.

Previous studies evaluated the persistence rate of antiglaucomatous medication in order to compare the efficacy of these treatments under controlled circumstances, and to identify whether adherence was better with one of the treatments. The conclusions of those studies varied as a result of variability in the prescribed dosage, patient interviews, and/or chart notation of medical decisions to substitute, add, or reduce medications, or to intervene with a laser or surgical option ${ }^{(5,23-25)}$.

For topical glaucoma medications, persistence may be considered a surrogate marker for physician satisfaction with IOP control and patient tolerability. Therefore, high IOP and/or intolerance may be the most frequent causes of discontinuing the medication, but considering the frequent failure of patient chart notation to indicate this and other critical information related to glaucoma, a prospective study is necessary to address this matter ${ }^{(26)}$.

The discontinuation rate of glaucoma medications after 12 months observed in this study (62.5\%) is similar to other studies $^{(18,27)}$. Although patients who experienced clinical worsening were more likely to discontinue initial therapy within the first six months (although this result was statistically insignificant), it would be difficult to determine the direction of causation, i.e., whether aggressive evolution of POAG would have lead to an early change of the initial prescription, or instead whether low adherence, therapy readaptation, and periods without IOP control lead to disease worsening.

In an ideal scenario, ophthalmologists would not have to make the decision of whether to change treatment strategy or continue with an unsatisfactory therapy ${ }^{(8)}$. Practitioners dealing with any chronic disease such as glaucoma might be able to recommend chronic medication based on persistence, along with as many other factors as possible. This will help to prevent periods of uncontrolled disease, periods of uncertain control, and excessive costs related to treatment changes ${ }^{(8,28)}$. In addition, health services might consider including the per- sistence of a therapy as a parameter for quality control of healthcare ${ }^{(26)}$.

Unlike in other studies, despite the free medical assistance provided in Brazil, patients had to purchase their own medication, and various classes of drugs were used ${ }^{(28-29)}$.

\section{CONCLUSION}

After concluding the present study, this referral center was directed by the governmental public health system to dispense all antiglaucomatous medications free of cost to the patients. Therefore, it would be interesting for further studies to examine the effect of government subsidized treatment on the persistence rate of treatment and on glaucoma progression.

\section{RESUMO}

Objetivo: Avaliar as mudanças terapêuticas, dadas por decisão médica, relativas ao tratamento do glaucoma primário de ângulo aberto em um centro de referência e a possível relação entre a persistência do tratamento e progressão da doença em casos controlados com medicação. Métodos: Uma revisão de prontuários foi realizada em 65 pacientes com glaucoma primário de ângulo aberto encaminhados a um hospital terciário Os seguintes dados clínicos foram analisados: primeira medicação instituída, persistência com o tratamento inicial, melhor acuidade visual corrigida, índice "desvio médio" do campo visual, relação escavação/disco óptico e pressão intraocular. Os pacientes foram classificados em quatro categorias, a fim de se verificar a evolução clínica. Resultados: A média do número de visitas/ano foi de 4,4 $\pm 3,5$ e o período de seguimento foi de $40,7 \pm 22,8$ meses. A média de tempo persistência foi de 12,9 $\pm 13,9$ meses. Em seis e doze meses, respectivamente, $39,1 \%$ e $62,5 \%$ dos pacientes tinham interrompido o regime terapêutico inicialmente previsto, principalmente pela adição (42\%) ou mudança $(26 \%)$ do esquema terapêutico. Treze pacientes $(21 \%)$ evoluíram para uma pior categoria de glaucoma primário de ângulo aberto, no entanto, apesar desta tendência, nenhuma correlação significativa foi encontrada entre baixa persistência e agravamento do glaucoma primário de ângulo aberto. Conclusões: As taxas de persistência com o esquema terapêutico inicial foram baixas, quando medidas através das mudanças observadas por decisões médicas, durante o curso do tratamento. Uma melhor decisão terapêutica inicial é crítica, a fim de poder se oferecer um tratamento mais estável e eficaz para o glaucoma primário de ângulo aberto.

Descritores: Glaucoma de ângulo aberto/quimioterapia; Pressão intraocular; Cegueira/prevenção \& controle; Atitude frente a saúde; Comunicação; Cooperação do paciente; Relações médico-paciente; Avanço da doença 


\section{REFERENCES}

1. Heijl A, Leske MC, Bengtsson B, Hyman L, Hussein M. Reduction of intraocular pressure and glaucoma progression: results from the Early Manifest Glaucoma Trial. Arch Ophthalmol. 2002;120(10):1268-79. Comment in: Arch Ophthalmol. 2002;120(10):1371-2. JAMA. 20027;288(20):2607-8. Optom Vis Sci. 2002;79(12):741-2.

2. Van Buskirk EM, Cioffi GA. Glaucomatous optic neuropathy. Am J Ophthalmol. 1992;113(4):447-52.

3. Quigley HA. Number of people with glaucoma worldwide. Br J Ophthalmol 1996;80:389-393. Comment in: Br J Ophthalmol. 1996;80(5):385-6. Br J Ophthalmol. 1997;81(1):93.

4. Schwartz G. Persistency and tolerability of ocular hypotensive agents: population-based evidence in the management of glaucoma. Am J Ophthalmol. 2004;137(1 Suppl):S1-2. Comment in: Am J Ophthalmol. 2004;138(6):1093-4; author reply 1094 .

5. Friedman DS, Hahn SR, Gelb L, Tan JH, Shah SN, Kim EE, et al. Doctorpatient communication, health-related beliefs, and adherence in glaucoma results from the Glaucoma Adherence and Persistency Study. Ophthalmology. 2008;115(8):1327.1-3

6. Florentinus SR, van Hulten R, Kloth ME, Heerdink ER, Griens AM, Leufkens HG, et al. The effect of pharmacotherapy audit meetings on early new drug prescribing by general practitioners. Ann Pharmacother. 2007; 41(2):319-24.

7. Taylor SA, Galbraith SM, Mills RP. Causes of non-compliance with drug regimens in glaucoma patients: a qualitative study. J Ocul Pharmacol Ther. 2002;18(5):401-9.

8. Kobelt G, Jonsson L, Gerdtham U, Krieglstein GK. Direct costs of glaucoma management following initiation of medical therapy. A simulation model based on an observational study of glaucoma treatment in Germany. Graefes Arch Clin Exp Ophthalmol. 1998;236(11):811-21.

9. Realini T, Fechtner RD. 56,000 ways to treat glaucoma. Ophthalmology. 2002;109(11):1955-6.

10. Grant WM, Burke JF Jr. Why do some people go blind from glaucoma? Ophthalmology. 1982;89(9):991-8.

11. Demarco AL, Rodrigues ML, Demarco LA. Ophthalmologic profile of patients going into the glaucoma wing of an university service. Medicina, Ribeirão Preto. 2002;35:478-86.

12. Jönsson B. The health economics of glaucoma In: Jönsson B, Kriegltstein G editors. Primary open-angle glaucoma: differences in international treatment patterns and costs. Oxford, UK: Isis Medical Media; 1999.

13. Gullo RM, Costa VP, Bernardi L, Kara-José N: Visual conditions of glaucomatous patients in an university hospital. Arq Bras Oftalmol. 1996;59(2):147-50.

14. Coyle D, Drummond M. The economic burden of glaucoma in the UK. The need for a far-sighted policy. Pharmacoeconomics. 1995;7(6):484-9.

15. Eid TM, Spaeth GL, Bitterman A, Steinmann WC. Rate and amount of visual loss in 102 patients with open-angle glaucoma followed up for at least 15 years. Ophthalmology. 2003;110(5):900-7.

16. Oliveira A, Paranhos Junior A, Prata Júnior JA. Characteristics presented by patients on their first appointment at the Glaucoma Sector of Universidade Federal de São Paulo - UNIFESP. Arq Bras Oftalmol 2003;66(6):785-90.

17. Mello PAA, Mandia Júnior C, editores. 2ำ Consenso Brasileiro de Glaucoma de Angulo Abert [Internet]. São Paulo; PlanMark; 2005. [citado 2010 Jan 2]. Disponível em: http://www.sbglaucoma.com.br/pdf/consenso02.pdf

18. Dasgupta S, Oates V, Bookhart BK, Vaziri B, Schwartz GF, Mozaffari E. Population-based persistency rates for topical glaucoma medications measured with pharmacy claims data. Am J Manag Care. 2002;8(10 Suppl):S255-61.

19. Diestelhorst M, Schaefer CP, Beusterien KM, Plante KM, Fain JM, Mozaffari E, et al. Persistency and clinical outcomes associated with latanoprost and beta-blocker monotherapy: evidence from a European retrospective cohort study. Eur J Ophthalmol. 2003;13(Suppl 4):S21-9.

20. Baffa LP, Ricardo JRS, Dias AC, Módulo CM, Braz AM, Paula JS, et al. Tear film and ocular surface alterations in chronic users of antiglaucoma medications. Arq Bras Oftalmol. 2008;71(1):18-21.

21. Kim J, Dally LG, Ederer F, Gaasterland DE, VanVeldhuisen PC, Blackwell B, et al. The Advanced Glaucoma Intervention Study (AGIS): 14. Distinguishing progression of glaucoma from visual field fluctuations. Ophthalmology. 2004; 111(11):2109-16.

22. Rouland J-F, Hågå A, Bengtsson S, Hedman K, Kobelt G. What triggers change of therapy? In: Jönsson B, Krieglstein G, editors. Primary open-angle glaucoma: differences in international treatment patterns and costs. Oxford, UK: Isis Medical Media; 1999. p.161-8.

23. Tingey D, Bernard LM, Grima DT, Miller B, Lam A. Intraocular pressure control and persistence on treatment in glaucoma and ocular hypertension. Can J Ophthalmol. 2005;40(2):161-9.

24. Reardon G, Schwartz GF, Mozaffari E. Patient persistency with ocular prostaglandin therapy: a population-based, retrospective study. Clin Ther. 2003; 25(4):1172-85.

25. Schwartz GF, Reardon G, Mozaffari E. Persistency with latanoprost or timolol in primary open-angle glaucoma suspects. Am J Ophthalmol 2004;137(1 Suppl): S13-16.

26. Quigley HA, Friedman DS, Hahn SR. Evaluation of practice patterns for the care of open-angle glaucoma compared with claims data: the Glaucoma Adherence and Persistency Study. Ophthalmology. 2007;114(9):1599-606. Comment in: Ophthalmology. 2007;114(9)1597-8.

27. Reardon G, Schwartz GF, Mozaffari E. Patient persistency with pharmacotherapy in the management of glaucoma. Eur J Ophthalmol. 2003;13 Suppl 4: S44-52.

28. Reardon G, Schwartz GF, Mozaffari E. Patient persistency with topical ocular hypotensive therapy in a managed care population. Am J Ophthalmol. 2004; 137(1 Suppl):S3-12.

29. Chawla A, McGalliard JN, Batterbury M. Use of eyedrops in glaucoma: how can we help to reduce non-compliance? Acta Ophthalmol Scand. 2007;85(4):464. 